\title{
RESULTS OF ALTITUDE TRAINING IN BRITISH TRACK AND FIELD ATHLETES, 1972
}

\author{
P. R. TRAVERS, MB, BS, DPhysMed \\ St Luke's College, Exeter; \\ Convenor of Medical Sub-Committee, British Amateur Athletic Board \\ R. WATSON, PhD \\ Chelsea College of Physical Education, Eastbourne
}

In May 1972 the British Amateur Athletic Board sent a party of middle distance athletes to St Moritz with Denis Watts and Harry Wilson as coaches and ourselves. The purpose of this brief visit was to investigate the facilities available for training and to establish, if possible, the sort of training that would be most beneficial when the team arrivd for the final altitude training in August. It also provided an opportunity to determine the scope of the physiological tests that could be carried out to monitor the response of individual athletes to altitude training. We hoped, too that some feedback would be obtained from the athletes about their training after return to sea level.

This preliminary experience was invaluable; not only was it possible to investigate the training facilities outdoors on the track and in the weight training room, and to meet the officials responsible for these facilities, but also the results showed that it would be better not to use the high altitude training ground at Corviglia for the first few days. Furthermore, we established that daily high intensity (anaerobic) training was not contraindicated. This was interesting, since in 1967/68 during the preparation for the 1968 Olympic Games, it had generally been accepted that the first few days at altitude should include no hard work at all, and that anaerobic training should be introduced with care even after that. Indeed, when I went to Font Romeu, the sports medicine doctor there told me that it was extremely dangerous, and possibly harmful, to do any training at all for the first 14 days. Since our total duration of stay was going to be 11 days, that was one of the more helpful pieces of information!

We found that we would be able to carry out daily pulse and respiration rate measurements, blood pressure and urine $\mathrm{pH}$ checks even in an hotel bedroom, with haemoglobin estimations at regular intervals. (Indeed daily pulse, respiration rates, and blood pressure measurements had been used by one of us (PRT) at Font Romeu in 1967/68.) In addition the number of hours sleep during the night and a summary of the athlete's training during the previous day would be recorded. These tests were to be offered on a voluntary basis to athletes at St Moritz during the final three weeks altitude training in August.

Of the athletes who were in St Moritz in August, 16
(11 men and five women) attended regularly for the daily tests. The remainder either did not attend, or attended so irregularly or infrequently that no valid records could be obtained. These tests were carried out immediately after breakfast, and before the athlete started to train. In one or two instances when an athlete wished to start his training early, special provisions were made to carry out the tests earlier. We appreciate that the figures we obtained were not true resting values, but as the tests were carried out at the same time, and in the same circumstances on each day a comparison of the daily figures is valid.

\section{Results of Daily Tests}

\section{Pulse and respiration rates}

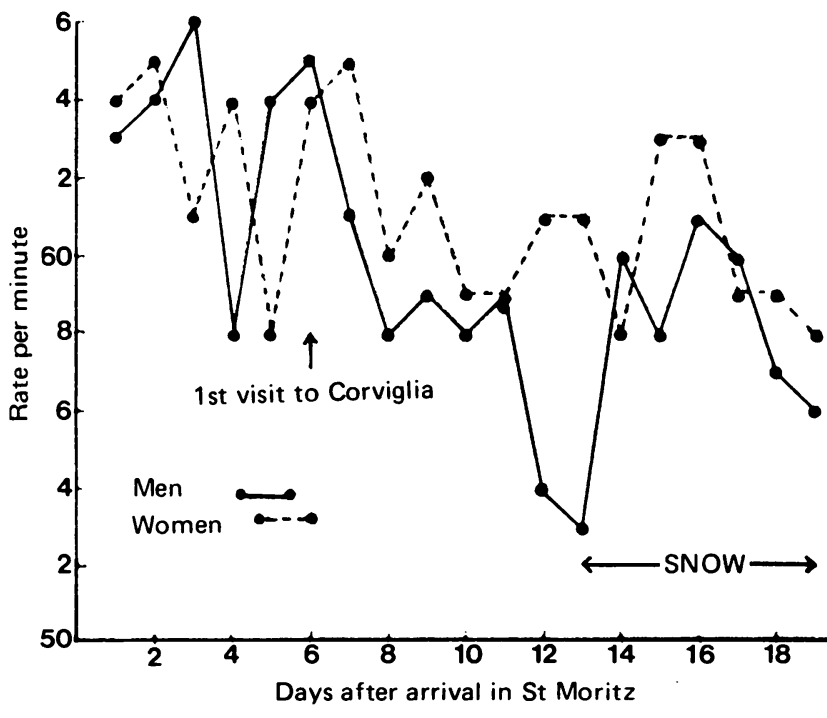

Fig. 1. Mean resting pulse rates.

The mean pulse rate fell from 63 on the first day to 56 on the 17th day for men, and from 64 to 59 for women (Fig. 1). The rise at the time of the first visit to Corviglia is interesting, and exactly corresponds with the figures obtained during the visit in May. We must point out that the latter part of the stay in St Moritz was marred by snow. 


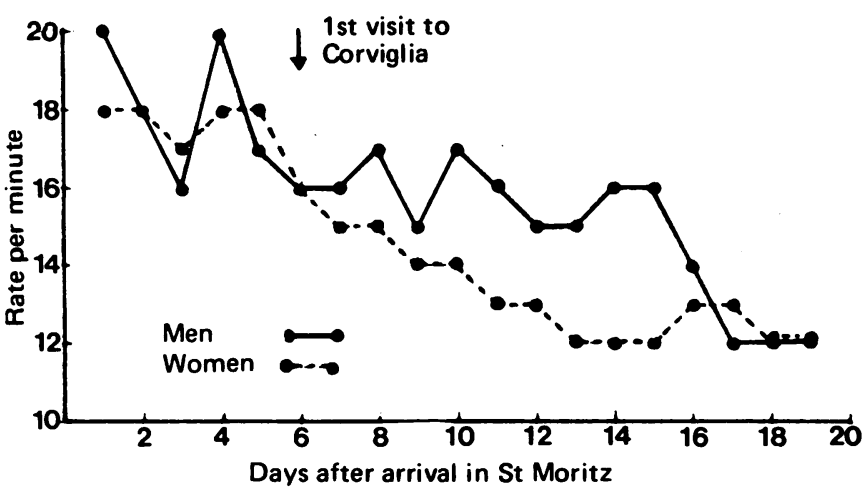

Fig. 2. Mean resting respiration rates.

With the respiration rates, too, there was a regular and progressive fall for both men and women. From 20 to 12 for men and from 18 to 12 for women (Fig. 2).

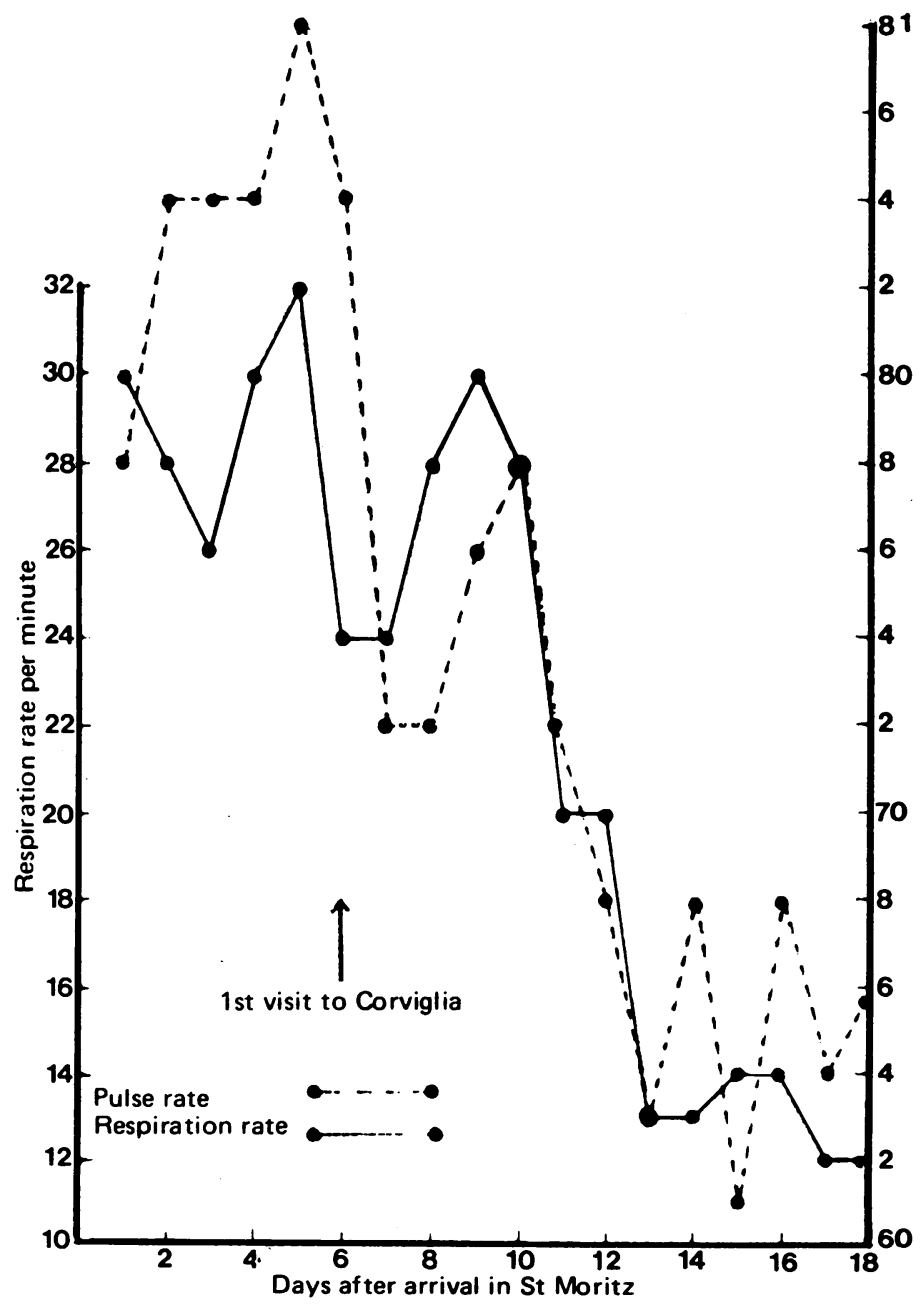

Fig. 3. The resting pulse and respiration rates of an asthmatic athlete (male).
A very interesting feature was the response of one athlete who was an asthmatic. His resting pulse rate on arrival was 78; it rose during the first four days to 88 , and then fell dramatically to 72 on the next day and eventually to 66 (Fig. 3). Figures from previous physiological tests carried out at St Luke's College, indicate that his resting pulse rate at sea level is around 60. His respiration rate dropped from 30 on day one to 12 on day 16 . We would point out that he was training very hard during the whole of this period, and that he made considerable use of the training ground at Corviglia even during the snow.

\section{Blood Pressure}

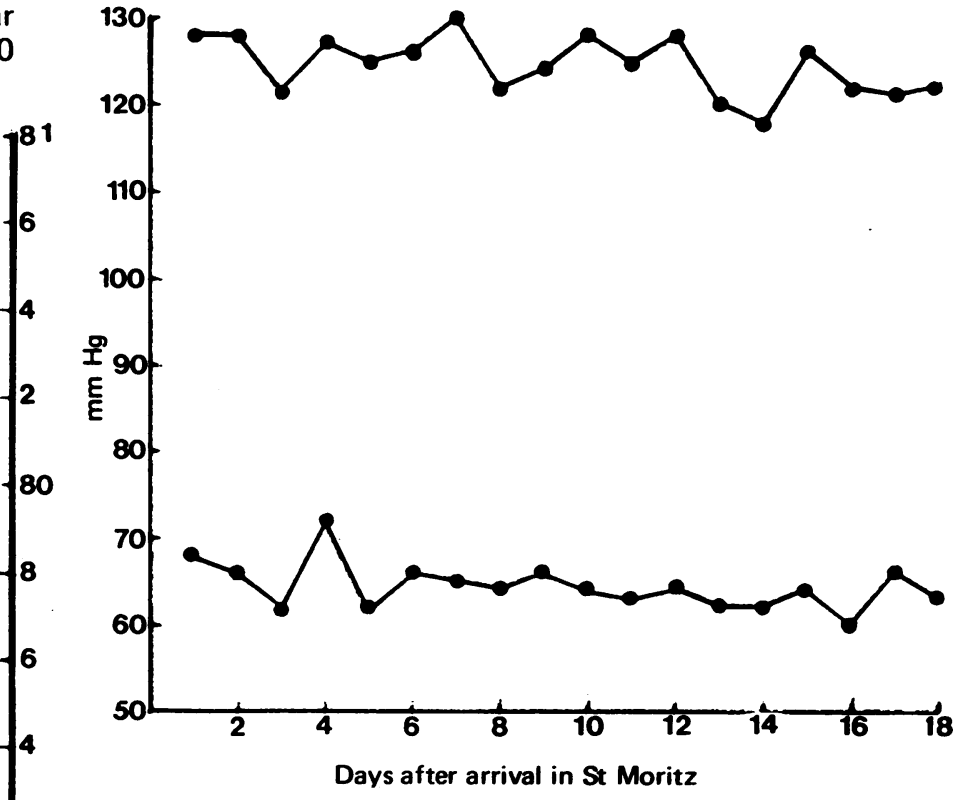

Fig. 4. Mean resting systolic and diastolic pressures (men).

There was virtually no change in either the systolic or diastolic pressures of the men (Fig. 4). However, both systolic and diastolic pressures of the women fell from a mean of 132 to 118 and from 76 to 57 respectively (Fig. 5).

\section{Haemoglobin Levels}

Probably the most interesting results were:obtained from investigating the haemoglobin. The mean level for both men and women fell during the first $\mathbf{1 0}$ days and then rose again. The mean for both groups was higher at the end of the stay than at the beginning (Fig. 6).

Further analysis showed that those athletes who arrived in St Moritz with a high haemoglobin level lover $14.8 \mathrm{~g}$ per $100 \mathrm{ml}$ for men and $13.8 \mathrm{~g}$ per $100 \mathrm{ml}$ for women) showed this fall during the first part of the stay. 


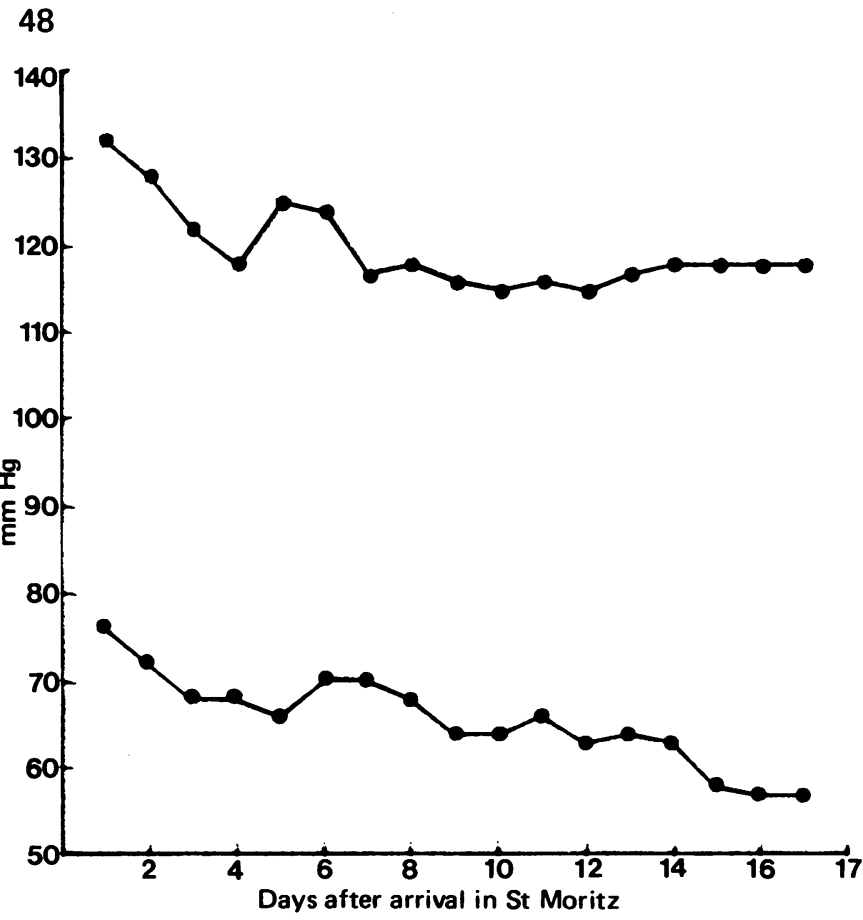

Fig. 5. Mean resting systolic and diastolic pressures (women).

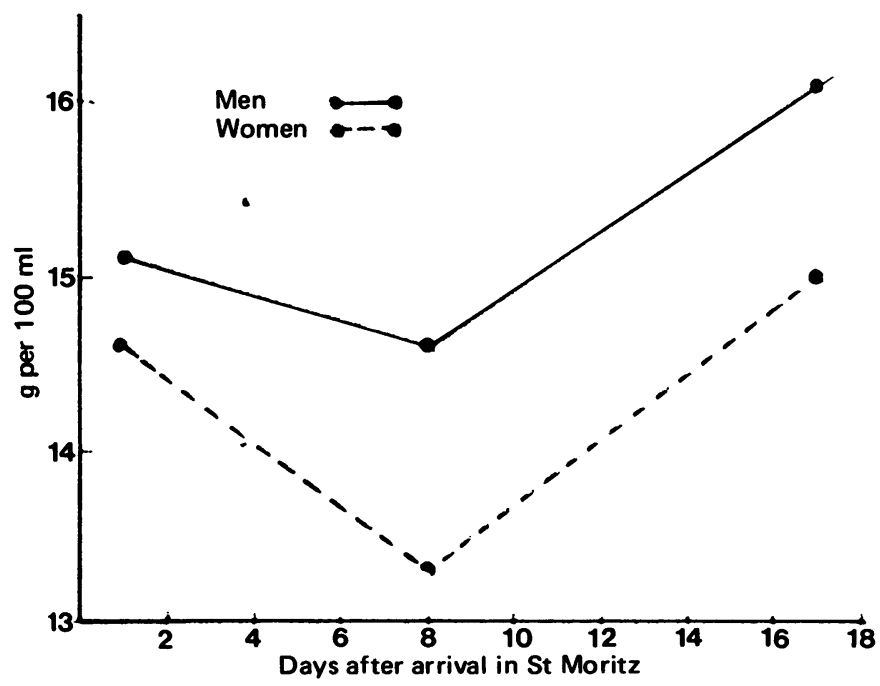

Fig. 6. Mean haemoglobin levels.

In the case of the men the final level for this group was below that on arrival (Fig. 7). However, those who arrived with a low haemoglobin level showed a steady increase during the time at altitude. Similar results were obtained from the women: those who arrived with a high haemoglobin level showed the fall during the first part of the stay, followed by a rise to just above the initial level. One athlete who arrived with a low level showed a steady improvement throughout (Fig. 8). This is, we feel, important since a stay at altitude of less than 17 or 18 days could result in an athlete returning to sea level with a haemoglobin level in the blood below that at the start of altitude training.

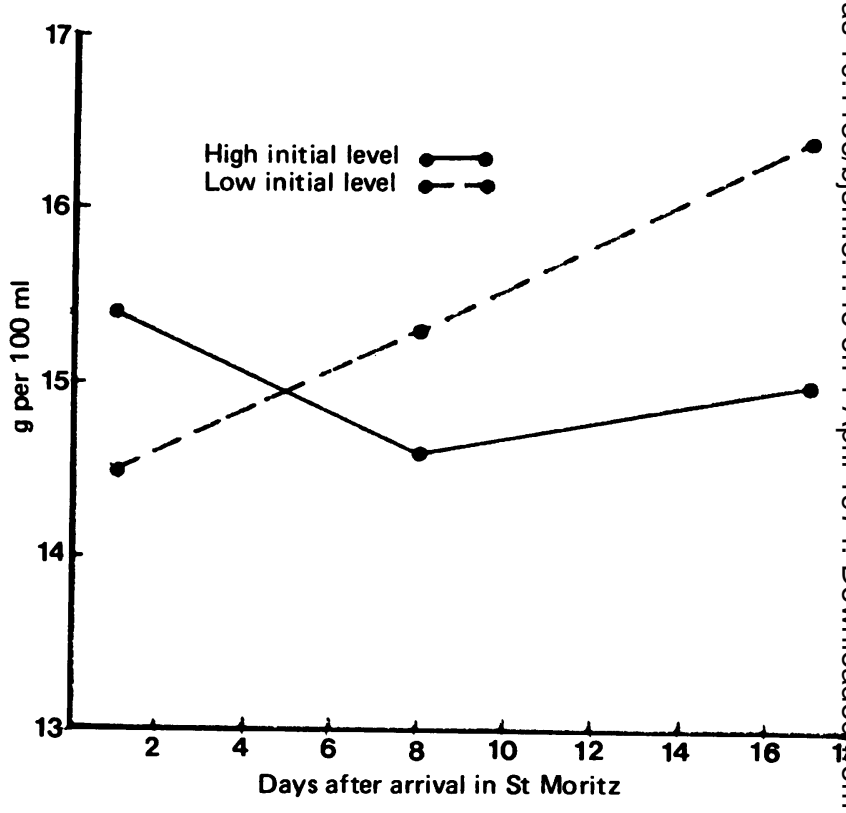

Fig. 7. Mean haemoglobin levels of those athletes (men) who arrived in St Moritz with high levels and with low levels.

\section{Urine $p H$}

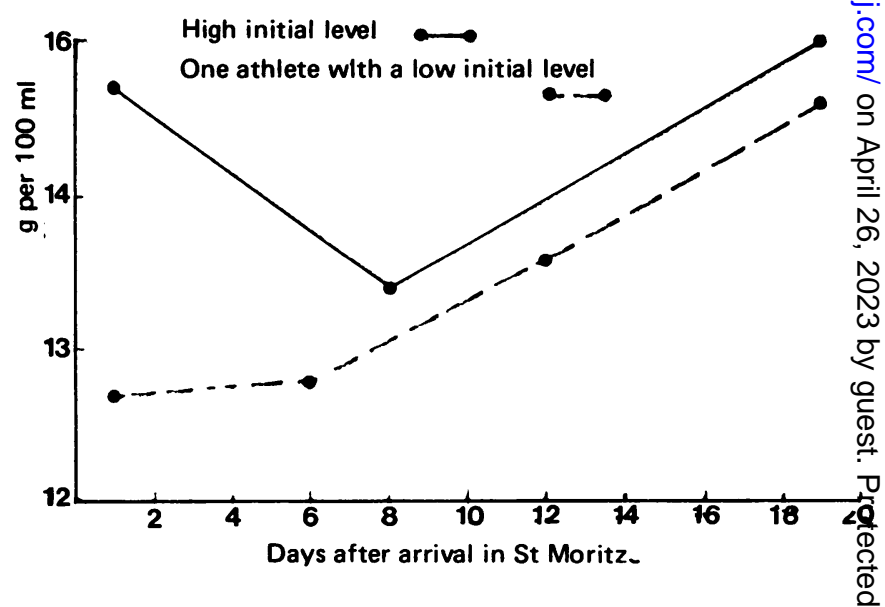

Fig. 8. Mean haemoglobin levels of those athletes (women) who, arrived in St Moritz with high levels and of one woman athlete who arrived with a low level. 
There was a considerable fluctuation, which depended upon the training that had been done on the previous day, in the $\mathrm{pH}$ of the urine. Initially the mean value was 6.0 for the men, but urine tests were not started for the women until day 6 , when the mean value was 6.1 . After the first training session at Corviglia the mean value was 7.0, with two athletes recording 8.0; at the end of the stay the mean value was 6.1 . It must be noted that an accurate $\mathrm{pH}$ meter was not available and that a colorimetric method was used. The value after the first visit to Corviglia indicated bicarbonate excretion due to hyperventilation during exercise at the increased altitude.

\section{Sleep}

Two men and two women experienced some trouble in sleeping during the first two nights. Thereafter there were no sleep problems that could be related to altitude.

\section{Telemetering of Heart Rate during Training}

This was carried out on a number of occasions, particularly with the walkers. Pulse rates of around 180 - 185 were obtained during time trials. No abnormal work electrocardiograms were obtained, and pulse recovery rates were highly satisfactory.

The response to training of the majority of athletes was entirely satisfactory. It is, however, impossible to comment accurately on those who did not attend regularly for tests. As an example of the results obtained, two $5,000 \mathrm{~m}$ walk time trials may be instanced. On August 24, Paul Nihill and Phil Embleton recorded times of 21:06.8 and 21:38.8 respectively. These are good times for a track walk of this distance, and it is of interest to note that in South Africa after 16 days at altitude on a previous occasion, Paul Nihill had only managed to clock 22:31.0 for the same distance. During the stay at St Moritz, Phil Embleton and Peter Marlow went down to Lugano for a competition in which they finished 1 st and 2 nd in an international field. The winning time was only just outside the record for the course. Very satisfactory time trials were also recorded by the runners, and notably by John Kirkbride.

\section{Re-adaptation to Sea Level}

This is an area in which we can find very little evidence of any research at all. Yet we believe that this period may determine the success or failure of altitude training.

We are perfectly satisfied that the athletes were extremely fit when they went down to Munich, yet their performances did not match up to that standard of fitness. In general they performed no better than the athletes in similar events who had not been at altitude. Only Brendan Foster in the $1,500 \mathrm{~m}$ semi-final, Margaret
Coomber in the $800 \mathrm{~m}$ heats, Rosemary Wright (Stirling) in the $800 \mathrm{~m}$ final, Joyce Smith in the $1,500 \mathrm{~m}$ semi-final, and Sheila Carey in the $1,500 \mathrm{~m}$ semi-final and final improved on their previous best performances. Nevertheless, we were still the only country in the world to have a finalist in every endurance event.

We are unable to comment upon the physiological response of the athletes to sea level after their period of altitude training as we were not members of the Olympic Team; indeed we were in St Moritz as BAAB coaches, with strict instructions that we were not to comment in any way on health matters, or to advise athletes on any injury problems. (After the departure of the main party to Munich, one of us (PRT) was asked to take over full medical, physiotherapy, and administrative duties.) We therefore had no access to the athletes in the Olympic village, and were unable to continue daily tests.

We can, however, record the feedback that we obtained from team members, and also that from athletes who went to St Moritz in May. They all reported very considerable difficulty in training during the first eight days after return to sea level, with very early onset of local muscle fatigue. It is unfortunate that we took little heed of the information obtained from athletes who went to St Moritz in May, since it is clear that by the fifth day at sea level they were still having problems, and that times in training were only just beginning to improve. The mass of the experimental evidence had indicated that five days at sea level was the optimum time before competition, and we thought that as our sample was extremely small, and was obtained from athletes who had been at altitude for only five days, we must discount our own results.

\section{Conclusions}

We now feel that we were wrong to discount our results, and that five days at sea level is far too short a time after altitude training and before competition. We do not know exactly what adaptive changes occur, and we certainly need to know far more about this early onset of local muscle fatigue. We also must determine the optimum training for athletes during this critical period. That a stay of more than five days at sea level is necessary is suggested by the fact that a number of athletes recorded better times after the end of the Games; notably Andy Holden broke the United Kingdom steeplechase record at a meeting at the Crystal Palace.

Accordingly, together with Denis Watts, we have submitted a paper to the BAAB and to the BOA outlining the experimental work that we consider essential before the next Olympic Games. It is now a matter of obtaining the necessary financial backing. We feel that this research must be carried out by a team who 
are known to British athletes, and that British athletes should be involved. The doubts that were expressed by a number of athletes after the Munich Games (admittedly often by those who were disappointed with their performances in the Games) concerning the expertise of those who were responsible for the direction of the training at St Moritz were very real. We must, for once, do our own research and not rely upon the work of others.

\section{DISCUSSION}

DR TRAVERS: To underline these problems of training on return to sea level my good friend, Stephen Hollings, has kindly agreed to recount his problems.

MR STEPHEN HOLLINGS: The feelings I experienced on arrival at Munich were also expressed by many of my colleagues who had been to St Moritz; they were basically of let-down. St Moritz was probably the greatest training area to which most of us had been. We arrived down at Munich to a massive complex with no grass, no lakes, and no mountain scenery. This was depressing for a start. Many of us were experiencing our first Olympic Games also, and it was all rather overawing.

I suffered bad headaches while in Munich - for the first five days before my competition - as did many other team members. Listlessness was a problem, and I also had difficulty in sleeping.

At St Moritz training was a joy and we really enjoyed going out. I am afraid that at Munich it was a case of having to force myself and getting other people to ask whether I was coming out training - we just did not want to train at all. Many people experienced this; we had to go out in groups and make each other train. Morale was getting very low.

Certainly my muscles felt very stiff when training in Munich. Cardiovascularly, it was superb and I did not seem to breathe, by my legs would not seem to go with it. That was the general feeling.

DR NORMAN MacLEAN (Doctor to British Winter Biathlon Team): Can you tell us how many athletes who beat others had had altitude training?

DR TRAVERS: I am afraid I have no figures for this.

MR WILSON: I can tell you that. Of the Finnish athletes, Vassala had spent approximately three months at altitude, and Viren had spent almost the entire previous winter at altitude.

Before the European championships the previous year Vaatainen had spent almost nine months in various places Mexico and other places around the world. Bragina, who set that astonishing world record in the women's $1500 \mathrm{~m}$, had spent three periods at altitude. Gamoudi, of course, is almost a permanently based altitude athlete and, so are Jipcho, Keino, and others such as Yifter.

MR CHRISTOPHER BRASHER: Could Dr Travers comment on Paul Nihill and Ron Hill, in particular whether he had any contact with them before their event? I am trying to discover any feeling they might have had of let-down. How did they feel when they went down to Munich? What was the gap between St Moritz and their events?

DR TRAVERS: I was with Paul Nihill more or less the whole time at St Moritz. I have given you his time trials two days before going to Munich. He went down absolutely convinced he would win a gold medal, and probably break the world record as well. As I said, I had no contact with the athletes from the day they left St Moritz. Nihill went down five days before his first race and, of course, stayed down for the second walk which was towards the end of the Games when, comparatively, he did very much better.

I had no knowledge of Ron Hill at all because he was one of the athletes who did not attend for testing. As a result of his first experience in St Moritz in May, he had decided that he would like to stay up for an additional period. Special arrangements were made for him to do this, and he went down exactly five days before the marathon. This was his own wish.

Don MacGregor went down much earlier, and by comparison did much better. 